Work related disorders

\section{Beyond the duality of disease and illness in occupational medicine}

\section{S Santana}

\section{Commentary on the paper by Coggon (see page 281)}

T his article addresses how changes in occupational morbidity are demanding new research approaches to provide relevant contributions for workers' protection and the improvement of workers' health standards in contemporary society. This is a necessary and timely reflection considering that at the turn of a new century, occupational diseases and injuries still represent a relevant health burden in most countries, challenging researchers and policy makers for more appropriate studies and effective actions. In this issue, $\operatorname{Coggon}^{1}$ points to: (1) the fact that current prevailing occupational diseases are musculoskeletal disorders and occupational stress; (2) their distinct relation to work risks, unclear ties between disease and illness expressions, and evidence of association with emotional factors; and hypothesises that they are not diseases (a biomedical concept based on objectively recognisable abnormalities), but illnesses (a subjective state of discomfort and suffering), a distinction proposed by Field $(1976)^{2}$ and Susser (1973). ${ }^{3}$ Most controversial is the author's statement that these occupational diseases are resulting from increased public awareness and media publicity related to the potential risks generated by technological innovation, which leads him to conclude that resources might be spent more effectively on programmes aimed at modifying cultural beliefs and expectations rather than trying to modify or reduce putative risks in the workplace.

The increase of the burden of musculoskeletal disorders and occupational stress is a well documented issue, but the explanations Coggon presents are not quite clear or convincing. First, the statement that the risk approach has been successful in controlling occupational risks is open to question; some authors have shown, for example, that downward trends of fatal accidents may be a result of changes in the production structure that are occurring in developed or developing countries. ${ }^{45}$ Under the restructuring of production, a major aspect is the elimination or reduction of manufacturing jobs, known for their hazardous chemical and physical exposures, and an increase in service oriented jobs, where ergonomic risks and psychosocial stressors are prevalent. Second, there is a growing number of studies showing that risks in the service trade arise not only in the relationships between man and machine, but also in the ways work is organised, co-workers' relationships are shaped, and how power distribution is democratically managed, particularly in relation to workers' control. ${ }^{6}$ "Flexibilisation" the reduction of stable jobs and their replacement by flexible forms of employment, such as self-employment, subcontracting, or alternative states of full-time, part-time, and unemployment-is also part of this restructuring process. ${ }^{78}$ In large corporations, work redesign reduces personal contact and social interaction, creating isolation and alienation." These and several other aspects of this new "work world" have been shown to provoke psychological disorders, stress, and stress related somatic diseases. ${ }^{6}$ Therefore, it is not plausible to think that the increase in occupational stress diseases derives solely from amplified awareness of work hazards disseminated by media sensationalism. In addition, the somatising tendency Coggon mentions may explain individual illness, but there is no current empirical evidence that somatising tendency is sufficiently prevalent or distributed in a way that explains the patterns of modern occupational illness.

There is no doubt that occupational medicine advanced with the development of toxicology and that the discovery of hazardous effects of toxic chemicals prompted professionals to eliminate or reduce exposures. A similar paradigm flourished in the beginning of public health when infectious diseases were widely preventable using the strategy of avoiding contact with biological agents. At that time, diseases were more relevant than illnesses and the search for a single pathogenic agent was the focus of investigation and the basis of prevention and treatment. Although social determinants are important for every single pathology, the increase of non-transmissible chronic diseases forced researchers and health professionals to consider more complex and dynamic pathogenesis processes that have strong interfaces with social relations, behavioural and psychological factors, perceptions, attitudes, and culture. ${ }^{10}$ It is not surprising that analogous changes have been also observed in occupational health where acute toxic syndromes are giving place to chronic long term effects with insidious onset and non-specific symptoms, which are largely modulated and mediated by social, behavioural, and psychological factors, as exemplified by stress related and musculoskeletal disorders. As a result, there is a growing interest in the study of subjectivity, and psychological and cultural aspects that advances the concept of health beyond reducionistic biological models ${ }^{10-12}$ and seeks to overcome the duality underlying disease and illness concepts.

In sum, the lack of objective detectable or measurable biological evidence, as for mental diseases, is not a requirement for their recognition and acceptance of relevant evidence of human suffering. Resources and efforts need to be directed towards a better understanding of the nature of these prevailing occupational diseases which perhaps requires a radical change in the way we think and conceptualise disease, illness, sickness, and disability. Besides improvement in assessment and diagnostic instruments, qualitative research approaches and participatory research focusing on workers' representation and their symbolic language may contribute to true advances in both theoretical and applied studies.

Occup Environ Med 2005;62:284-285

doi: 10.1136/oem.2004.019034

Correspondence to: Dr V Santana, Instituto de Saúde Coletiva/UFBA, Rua Augusto Vianna s/n 2 ${ }^{\circ}$, Andar, Salvador Bahia 40-110-040, Brazil; vilma@ufba.br

Competing interests: none declared

\section{REFERENCES}

1 Coggon D. Occupational medicine at a turning point. Occup Environ Med 2005;62:281-3.

2 Field D. The social definition of illness. In: Tuckett D, ed. An introduction to medical sociology. London: Tavistock, 1976.

3 Susser M. Causal thinking in the health sciences. New York: Oxford University Press, 1973.

4 Loomis D, Richardson DB, Bena JF, et al. Deindustrialisation and the long term decline in fatal occupational injuries. Occup Environ Med 2004:61:616-21.

5 Wunsch-Filho V. Restructuring of production and occupational accidents in Brazil: structure and trends. Cad Saúde Pública 1999;15:41-52.

6 Johnson JV, Johansson G. The psychosocial work environment: work organization, democratization and health-Essays in memory of Bertil Gardell. New York: Baywood Publishing Company, 1991

7 Oechsler WA. Workplace and workforce $2000+$ - the future of our work environment. Int 
Arch Occup Environ Health

2000;73(suppl):S28-32

8 Quinlan M, Mayhew C, Boyle P. The global expansion of precarious employment, work disorganization, and consequences for occupational health: a review of recent research Int J Health Services 2001;31:335-413.
9 Siegrist J, Marmot M. Health inequalities and the psychosocial environment-two scientific challenges. Soc Sci Med 2004:58: 1463-73.

10 Almeida-Filho NM. For a general theory of health: preliminary epistemological and anthropological notes. Cad Saúde Pública 2001;17:753-99.

\section{Occupational medicine: at a turning point or an expansion}

A Blair

\section{Commentary on the paper by Coggon (see page 281)}

D avid Coggon, in his editorial on "Occupational medicine at a turning point", ${ }^{1}$ makes a number of insightful observations and thoughtful suggestions regarding health and hazards in the workplace. He notes that "As many of the most serious occupational hazards have been successfully addressed, attention has shifted increasingly to other work related disorders that are rarely fatal". He points out that the human and economic costs of these less fatal conditions are considerable and that the current research and intervention models may require some rethinking to deal effectively with them. I found his discussion and recommendations on this topic timely, and they will help the expansion of occupational research into this new area.

Considerable progress has been made on reducing and eliminating many serious occupational hazards, particularly in developed countries. It may, however, be premature to assume that chemical and physical hazards are under control. The understanding of occupational exposures in the development of chronic diseases and conditions is far from complete. Cancer has received much more attention than neurological, immunological, reproductive, and developmental outcomes, but even for cancer, there are areas where the literature is quite limited. However, for cancer, I think a compelling case can still be made for the need for further work on occupational risk factors. First, occupational exposures and cancer among women, minorities, and workers in small businesses and in developing countries have not been studied nearly as intensively as among white men in developed countries. Although the impact of some, maybe most, occupational exposures may not differ among population subgroups, we need a considerably firmer database before we conclude that findings for one group can stand for all. Second, the changing nature of the workforce, manufacturing processes, and the geographical location of many industries further underscores the need for future research among these under-investigated groups. Third, although some 30 different substances are well recognised as occupational carcinogens, there are hundreds more under suspicion where the available evidence is inconclusive. Fourth, there are many occupations where cancer appears to be excessive, but where the hazardous agent has not been identified. Finally, we have barely started to evaluate risks from multiple exposures. These limitations apply even more strongly to non-malignant diseases.

Occupational diseases are sometimes portrayed as only a minor contributor to the disease burden of the population. The 1981 estimate by Doll and Peto ${ }^{2}$ that $4 \%$ of cancer deaths in the United States may be due to occupational causes is still widely accepted and is probably a reasonable estimate for other developed countries. This $4 \%$ estimate for cancer is sometimes used to argue that occupational exposures are too unimportant to receive much research attention given finite resources. There are a number of arguments against this assertion. First, only tobacco and diet account for a radically different proportion of cancer deaths at $30 \%$ and $35 \%$, respectively. According to Doll and Peto, attributable proportions from other established risk factors are 3\% for alcohol, $7 \%$ from reproductive behaviours, $2 \%$ from pollution, $1 \%$ from medicines and medicinal procedures, 3\% from geophysical factors, and perhaps $10 \%$ from infections. Yet these factors are seldom dismissed as unworthy of further investigation. Second, as pointed out by Doll and Peto, occupational exposures are unevenly distributed across the workforce. According to the 1950 census, about $18 \%$ of the employed population held
11 Wade DT, Halligan PW. Do biological models of illness make for good healthcare systems? BMJ 2004;329: 1398-401.

12 Samaja J. Epistemologia de la Salud-reproducción social, subjetividad y transdisciplina. Buenos Ayres: Lugar Editorial, 2004.

blue-collar jobs; this has fallen to $13 \%$ in 2000. Since blue-collar occupations are where most of the hazardous exposures are likely to occur, it stands to reason that this is also where the bulk of occupationally related cancer arises. Thus, the proportion of cancer in bluecollar workers due to occupational exposures is probably $5-8$ times that of the overall population estimate. Thus, the proportion due to cancer in bluecollar workers could be $20-30 \%$. Finally, occupational exposures are largely involuntary and can be controlled. Availability of calculations of proportion of cancer caused by occupational exposures in the literature underscores the amount of scientific attention cancer has received, and the more limited effort and clear need for further research on occupational causes of other chronic diseases.

Dr Coggon suggests that the involvement of societal/cultural beliefs in the development of illnesses (conditions that are not a pathological state but an "absence of wellbeing") indicates that if control of exposures is not effective in reducing the occurrence of the illness, modification of cultural beliefs and expectations offers another approach. The dual approach may also have relevance to chronic diseases. There are a number of examples where such psychosocial or cultural factors interact with traditional aetiological agents to modify risk of infectious and chronic diseases. $^{3}$ The recognition that both factors may be involved enhances preventive opportunities because control over illnesses could be achieved by effective manipulation of either impetus. As indicated by Dr Coggon, epidemiological investigations can, and should, evaluate this possibility.

Occup Environ Med 2005;62:285 doi: 10.1136/oem.2004.018382

Correspondence to: $\operatorname{Dr}$ A Blair, Occupational and Environmental Epidemiology Branch, Division of Cancer Cause and Prevention, National Cancer Institute, Executive Plaza South, Room 8118, Bethesda, MD 20892, USA; blaira@mail.nih.gov

Competing interests: none declared

\section{REFERENCES}

1 Coggon D. Occupational medicine at a turning point. Occup Environ Med 2005:62:281-3.

2 Doll R, Peto R. The causes of cancer. New York: Oxford University Press, 1981.

3 Schneiderman N Antoni MH, Saab PG, et al. Health psychology: psychosocial and biobehavioral aspects of chronic disease management. Annu Rev Psychol 2001;52:555-80. 